\title{
STREAMLINING ORGANIG SEED PRODUCTION TECHNOLOGIES FOR VEGETABLE SPECIES BY MAKING SEED CONDITIONING MODULE
}

\author{
Gheorghe Stroescu, Anisoara Paun, Carmen Bracacescu, Mihai Olan \\ National Institute of Research-Development for Machines and Installations \\ Designed to Agriculture and Food Industry, Romania \\ gigistroescu62@gmail.com, ani_paun@yahoo.com, carmenbraca@yahoo.com
}

\begin{abstract}
Ensuring for production the necessary quantities of biological material of valuable varieties and hybrids to maintain their initial characteristics requires permanent application of measures to be carried out on a scientific basis, depending on the biological particularities of the variety or hybrid, in a predetermined system, called "production of seeds and propagating material". Obtaining satisfactory results in the production of seed and planting material, organic certified, depends not only to a large extent on the functional quality of the equipment and the seed conditioning installations, but also on the quality of the personnel involved in the production process. Compared to other vegetable crops, vegetable seeds are produced in small quantities (except beans, peas, lentil, etc.) and their characteristics (length, width, thickness, etc.) are various. Therefore, the vegetable seed conditioning requires complex technologies and installations to ensure high quality sowing material. The paper presents some theoretical aspects regarding seed mixture conditioning, which led to the elaboration of an innovative technology for the production of organic seeds for the vegetable species and to a new type of seed conditioning module MCSL made at INMA Bucharest. The conditioning module, consisting mainly of an aerodynamic sorting machine, a sort evacuation system and a work platform, is intended for vegetable species and performs seed cleaning of light impurities by removing them in two fractions and sorting the product in three fractions. These operations can be performed by one or more passages of the useful fractions through the machine, depending on the pre-cleaning degree and the destination of the seeds. At the end of the paper the advantages of using this new type of vegetable seed conditioning module are presented.
\end{abstract}

Keywords: seed, conditioning, aerodynamic properties.

\section{Introduction}

The production of seeds for leguminous plants is of great importance because the vast majority of species propagate in this way. Due to the fact that the production obtained depends on the quality of the seeds, it is necessary to use seeds of varieties and hybrids with superior qualities and of higher biological categories without foreign bodies (impurities).

Knowing the peculiarities of vegetable seeds is of particular practical importance, because depending on them the conditioning technologies are made and the crop technologies in the field as well as in the protected areas are directed. Seed quality is a relative notion because the seeds of some species may have different destinations: food or feed consumption, seeding or industrialization $[1 ; 2]$.

Propagating material in organic farming must be produced in organic certified seed crops where organic production methods are applied.

Seeds or planting material must meet standards in terms of physiological features (germination), physical characteristics (botanical composition, physical purity) and health status (pest infestation and pathogen infestation).

According to several papers from the literature [3-6], obtaining satisfactory results in the activity of producing seed and planting material, organic certified, depends largely on the functional quality of the equipment and the seed conditioning installations, as well as on the quality of the personnel involved in the production process.

The paper presents some theoretical aspects regarding seed mixture conditioning based on the aerodynamic principle, which led to the elaboration of an innovative technology for the production of organic seed for the vegetable species and the Seed conditioning module MCSL designed and realized at INMA Bucharest.

\section{Materials and methods}

Since vegetable seeds have a wide variety of shapes and sizes, it is preferable to use, in the conditioning process, equipment that operates on the principle of separation based on aerodynamic properties, since separation based on the size by using sieves involves a great financial effort (requires sieves with holes suitable for each species) [7]. 
It was found that on a solid particle in a vertical ascending airstream a series of forces (mass and surface) act, some of which being shown in Figure 1.

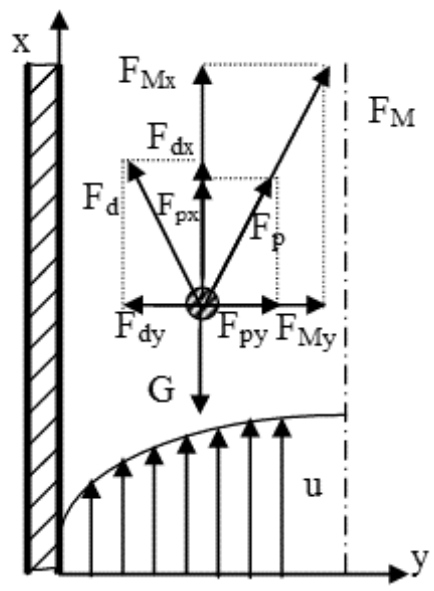

Fig.1. Distribution of forces acting on solid particle (seed assimilated to spherical shape) in turbulent vertical airstream: $G$ - weight force; $F_{d}$ - frontal dynamic pressure force; $F_{p}$ - bearing force; $F_{M}$ - Magnus force

From the analysis of these forces, which act on the solid particle in an airstream, it is noted that there are:

- mass forces that are proportional to the particle mass;

- surface forces, the module of which is proportional to the particle surface size.

Regarding the particles in a tube with a vertical ascending airstream, they are entrained by this airstream and will travel at different speeds depending on their shape and weight. The airstream bearing force can be determined in the following cases, as follows:

- for the laminar flow of the air, with Stokes relation:

$$
F=3 \cdot \pi \cdot \eta \cdot d \cdot v_{p}
$$

- for the turbulent flow of the air, with Newton's relation:

$$
F=k \cdot S \cdot \gamma_{a} \frac{v_{p}{ }^{2}}{g}
$$

where $\eta$-dynamic viscosity of air;

$d$ - particle diameter, m;

$v_{p}-$ relative velocity of the particle reported to that of the aerodynamic field, $\mathrm{m} \cdot \mathrm{s}^{-1}$;

$k$ - aerodynamic field drag coefficient;

$S$ - surface of the particle projection on a plane perpendicular to the direction of the movement speed, $\mathrm{m}^{2}$;

$\gamma_{a}-$ air density $\left(\gamma_{a}=1.2 \mathrm{~kg} \cdot \mathrm{m}^{-3}\right)$;

$g$ - gravitational acceleration, $\mathrm{m} \cdot \mathrm{s}^{-2}$.

In the case of equipment that uses as a separation principle the separation by aerodynamic properties, one should consider the seed and impurity floating velocities and also the aerodynamic coefficient, respectively [8]:

$$
\begin{gathered}
v_{p}=\sqrt{\frac{\rho_{p \frac{\pi d^{3}}{6}}}{0.124 k \frac{\pi d^{2}}{4}}} \\
v_{p}=2.4 \sqrt{\frac{\rho_{p}}{k} d},
\end{gathered}
$$


where $v_{p}$ - floating velocity, $\mathrm{m} \cdot \mathrm{s}^{-1}$;

$\rho_{p}$ - specific mass of the particle (spherical seed), $\mathrm{kg} \cdot \mathrm{m}^{-3}$;

$d$ - particle diameter, $\mathrm{m}$;

$k$ - aerodynamic drag coefficient (depends on the state of the particle surface).

Knowing the floating characteristics of seed mixture particles in airstreams gives important indications for choosing and correctly adjusting the speed of the airflow for calculating and designing pneumatic systems for sorting and cleaning the seed mixture.

\section{Results and discussion}

The organic seed production technology presented in Figure 2 was used in the design of a seed conditioning module for vegetable species MCSL, a module that helps cleaning vegetable seeds from light impurities and sorting the product. These operations can be performed by one or more passages of the useful fractions $\left(F_{1} \div F_{5}\right)$ through the machine, depending on the pre-cleaning degree and the destination of the seeds.

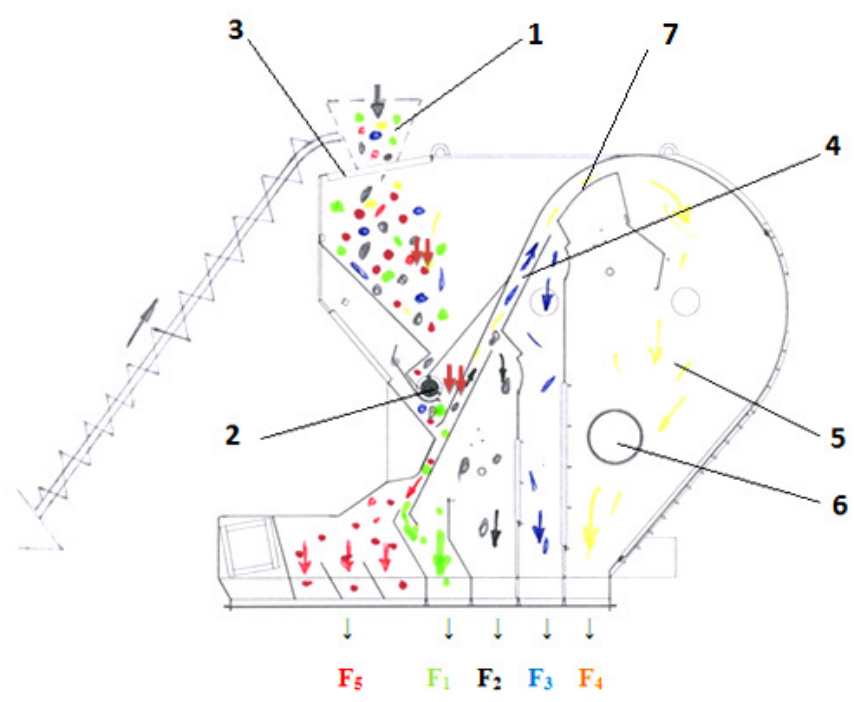

Fig. 2. Schematic representation of technology for obtaining organic seed [9]

The product to be sorted is brought into the feed hopper (pos. 1) and from here, by means of a cylinder (pos. 2) and a supply flap (pos. 3), it is distributed uniformly in the sorting column (pos. 4) with upward air created by a fan (pos. 6). Under the influence of the upward airstream, within floating velocities limits, the heavier bodies fall to the lower part to obtain the fraction $F_{1}$, the lighter ones ascend to the first orifice, where the fraction $F_{2}$ is separated, to the second orifice, where the fraction $F_{3}$ is separated or leave the column at the top entering the decanting chamber (pos. 5), where the $F_{4}$ fraction of lightweight bodies (impurities) is deposited.

The air sucked from the decanting chamber is pressed by the fan into the second deposition chamber, where dust and other very light impurities are separated forming the $F_{5}$ fraction. The five fractions pass through the discharge hoppers and the two locks in the exhaust pipes and then into the collecting bags.

The seed conditioning module for vegetable species MCSL (see Fig. 4) developed within the technology has the novelty that it performs the seed cleaning of light impurities by eliminating them in two fractions and sorting the product in three fractions. These operations can be carried out by one or more passages of the useful fractions through the machine, depending on the pre-treatment degree and the destination of the seeds.

Technical characteristics of MCSL, production capacity:

- vegetable and flower seeds: $12 \div 60 \mathrm{~kg} \cdot \mathrm{h}^{-1}$

- air velocity in the column: $0.5 \div 18.0 \mathrm{~m} \cdot \mathrm{s}^{-1}$ 


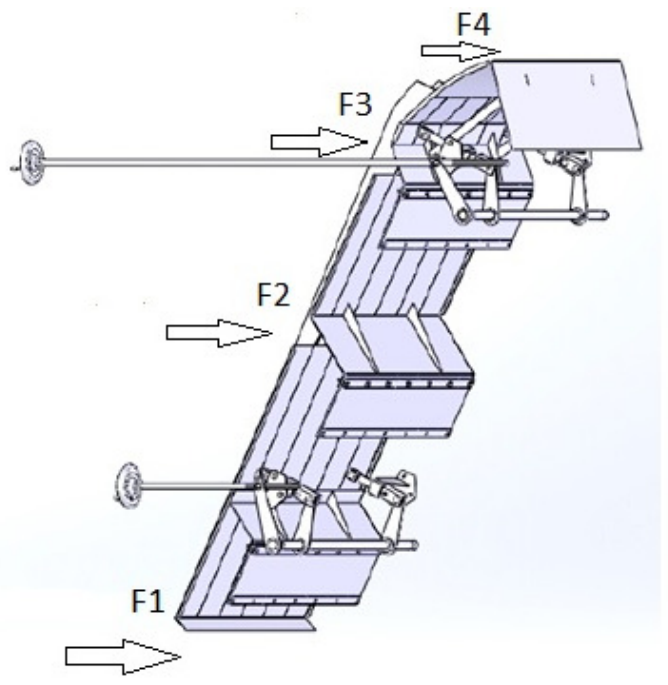

Fig. 3. Representation of product fractions through separation wall

a)

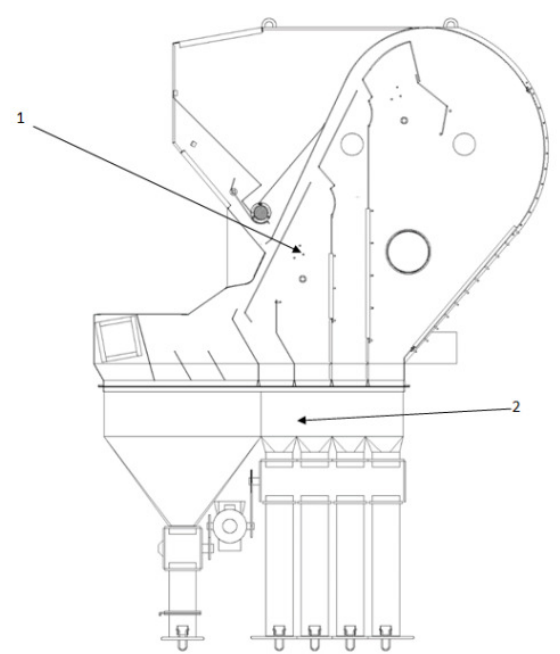

b)

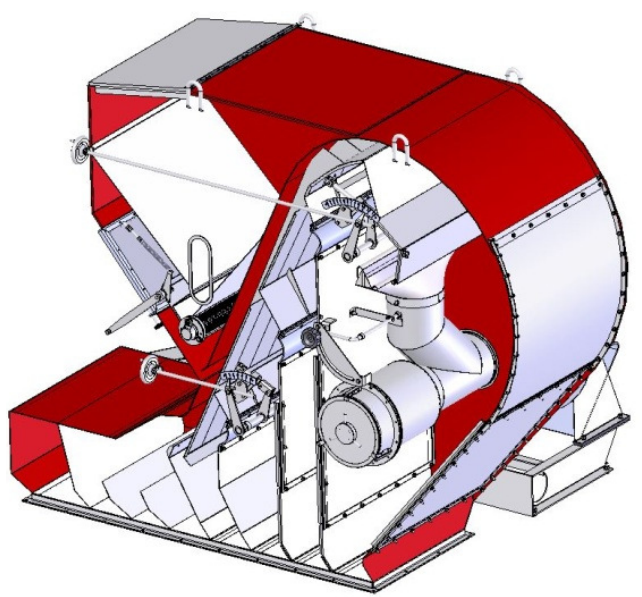

Fig. 4. Seed conditioning module for vegetable species MCSL [10] machine scheme(a); 3-D representation (b): 1 - aerodynamic sorter; 2 - sorts discharge system

\section{Conclusions}

1. The seed conditioning module for vegetable species MCSL has the following advantages:

- simple construction by removing electrically operated sieves;

- maintenance of vegetable seeds pre-cleaning is easy to make and at low costs;

- power consumption reduced by $20 \%$;

- low mechanical wear under operation due to elimination of mechanical transmissions.

2. The conditioning module can be used in plants for the production of vegetable, flower, cereal seeds as well as in agricultural companies or other units for cleaning and sorting products.

3. When implementing such technology in a seed conditioning plant, it should be considered that:

- the seeds must follow a technological flow in the various flow operations in a suitable logical sequence to avoid seed degradation by excessive manipulation;

- the possibilities of contaminating seed lots must be eliminated;

- in the case of conditioning expensive seeds, which are produced in small quantities for sowing (vegetables, flowers, medicinal plants), there must be the possibility for the valuable components that are cleansed to be recovered and used properly in food consumption, feed, etc. 


\section{Acknowledgements}

This paper was financed with:

- the support of the Romanian Research and Innovation Ministry, Programme FARMING FOR TOMORROW-ENSURING ENVIRONMENT SUSTAINABILITY THROUGH THE INCREASE OF IMPROVEMENT COMPETITIVENESS FOR ORGANIC FARMING (UEFISCDI PN-III-P1-1.2-PCCDI-2017- 0850, Contract: 14PCCDI/06.03.2018), project component 4 "Making efficient the technology of producing ecological seeds for legume species by achieving a module of seed conditioning",

- a grant of the Romanian Research and Innovation Ministry, through Programme 1 Development of the national research-development system, sub-programme 1.2 - Institutional performance - Projects for financing excellence in RDI, contract no. 16PFE.

\section{References}

[1] Bucurescu N., Roman D. Seed and its preparation for sowing, Ceres Publishing House, Bucharest, 1992.

[2] Ciofu R. et al., Dissertation on vegetable growing, CERES, Publishing House, Bucharest, 2004.

[3] Barsky E., Barsky M. Relationship between fractional separation curves and quantitative optimization criteria in the separation of pourable materials, Physical Separation in Science and Engineering, 2004, vol. 13, pp. 41-51.

[4] Căsăndroiu T. Primary processing and agricultural products storing, lithographed course, Politehnica University of Bucharest, 1993.

[5] Danciu I. Cereals cleaning, "Lucian Blaga" University Publishing House, Sibiu, 2001.

[6] Rus Fl. Separation operations in the food industry, Publishing Transylvania University of Brasov, ISBN-973-8124-31-X,2001, pp. 75-101.

[7] Didyh V.F. Improving the efficiency of drying agricultural plant materials: monograph, 2002, Lutsk pp.165.

[8] Zewdu A.D. Aerodynamic properties of the grain and straw material, Biosystems Engineering Journal, 2007, vol. 98, pp. 304-309.

[9] Stroescu Gh., Păun A. \&co. Technology for obtaining environmentally-friendly seeds and sowing material for vegetable species, Proceedings of international Symposium ISB-INMATEHAgricultural and Mechanical Engineering, 1-3 Nov. 2018, ISSN 2537-3773, pp.467-472;

[10] Păun A., Stroescu Gh., Bogdanof G., Vlăduţ N-V. Vegetable seed pre-cleaning module - patent application no. A-00986/28.11.2018. 